\title{
A regulação da pesquisa e o campo biomédico: considerações sobre um embate epistêmico desde o campo da educação
}

\author{
The research regulation and the biomedical field: \\ considerations about an epistemic clash from the \\ field of education
}

\section{La regulación de la investigación y el campo de la biomedicina: consideraciones acerca de un choque epistémico desde del campo de la educación}

\author{
Isabel Cristina de Moura Carvalho* \\ Frederico Viana Machado*
}

\begin{abstract}
Resumo: O presente artigo discute a regulação da ética em pesquisa, preconizada pelas resoluções 196/1996 e 466/2012 e o sistema CEP/CONEP, retomando debates realizados no campo das Ciências Humanas a partir da perspectiva da pesquisa em educação. Foram analisados dados sobre os cuidados éticos na pesquisa em 84 Programas de Pós-Graduação em Educação, filiados ao FORPRED, que responderam a um questionário online elaborado pelo fórum. Apresentamos argumentos construídos pelas Ciências Humanas, sobretudo pela Antropologia, ao longo da última década, e que consideramos fundamentais para a consolidação deste debate. Argumentamos que a regulação da ética na pesquisa deve ser tomada como parte de um processo mais amplo de demandas do campo das Ciências Humanas às agências reguladoras.
\end{abstract}

Palavras-chave: Ética na Pesquisa. Sistema CEP/CONEP. Pesquisa em Educação.

\begin{abstract}
This article discusses the research ethics regulations in contemporary Brazil, advocated by 196/1996 and 466/2012 Resolutions, and the CEP/CONEP System. We take into account the theoretical discussions in the Humanities and Social Sciences fields, from the educational research perspective. We analyze the ethical guidelines on research in 84 Postgraduate institutions, affiliated to FORPRED (Forum of PostGraduate Programs of Education) which answered to an online questionnaire, specially prepared by this Forum. We present arguments constructed by Humanities and Social
\end{abstract}

\footnotetext{
* Professora do Programa de Pós-Graduação em Educação da Faculdade de Educação da Pontifícia Universidade Católica do Rio Grande do Sul. E-mail: isabel.carvalho@pucrs.br>

** Pós-doutorando (PNPD/CAPES) e professor colaborador do Programa de Pós-Graduação em Educação da Faculdade de Educação da Pontifícia Universidade Católica do Rio Grande do Sul. E-mail: fredvma@yahoo.com>
} 
Sciences, especially in the Anthropology field, over the last decade, and we consider fundamental for the consolidation of this debate. We argue that the regulation of research ethics should be taken as part of a broader process in demanding regulatory agencies, by Social Sciences researchers.

Keywords: Research Ethics Regulations. CEP/CONEP System. Educational Research.

Resumen: Este artículo aborda la regulación de la ética en la investigación en Brasil, preconizada por las Resoluciones 196/1996 y 466/2012 y el sistema CEP/ CONEP. Hemos tomado los debates del campo de las Ciencias Humanas y Sociales desde la perspectiva de la investigación en educación. Fueron analizados datos sobre orientaciones éticas en la investigación de 84 programas de posgrado en educación, afiliados a FORPRED (Foro de Coordinadores de Programas de Pos Graduación en Educación), que respondieron a un cuestionario online, elaborado por este foro. Se presentan argumentos construidos en las Ciencias Humanas y Sociales, especialmente de la antropología, en la última década, que consideramos fundamentales para la consolidación de este debate. Se argumenta que la regulación de la ética en la investigación debe ser tomada como parte de un proceso más amplio de demandas de las Ciencias Humanas e Sociales a las agencias reguladoras.

Palabras-clave: Ética en la Investigación. Sistema CEP/CONEP. Investigación en educación.

\section{Apresentação}

Este artigo foi escrito para a Sessão Especial sobre "A Regulação da Ética na Pesquisa", promovida pelo Fórum de Coordenadores de Programas de Pós-Graduação em Educação (FORPRED) e o Comitê Científico da Associação Nacional de Pesquisa e Pós-Graduação em Educação (ANPED), durante a 36 Reunião Nacional (RN) da ANPED (Goiânia, 28/09 a 03/10 de 2013). Esta sessão marca a preocupação dos pesquisadores da educação com o debate em torno da regulação da ética na pesquisa pelas resoluções 196/96 e a atual 466/2012 do Conselho Nacional de Saúde (CNS). O campo da Antropologia tem liderado este debate que convoca o campo das Ciências Humanas a posicionar-se diante das formas de regulação da ética na pesquisa e suas implicações para o fazer científico. Neste artigo, nosso objetivo é sistematizar os argumentos que estão em pauta nesta conjuntura e contribuir para tomada de decisões entre os pesquisadores da educação.

Para tal, é importante diferenciar duas expressões que nos últimos anos têm pautado nossas preocupações acadêmicas sobre o cuidado e a responsabilidade na produção do conhecimento: "ética" e "integridade" na pesquisa. Embora 
associadas, na medida em que tratam dos fundamentos morais da prática científica e definem boas práticas, tratam-se de duas esferas diferentes. A integridade na Pesquisa diz respeito à conduta do pesquisador no tratamento dos dados e na publicação da pesquisa. É nesta esfera que se definem as orientações e normas que buscam evitar fraudes tais como o plágio, o autoplágio, a fabricação e/ou segmentação de dados, autoria indevida ${ }^{1}$.

Embora estes aspectos denominados de integridade na pesquisa digam respeito ao campo da ética, como horizonte norteador da conduta moral desejável do pesquisador cientifico, o que se convencionou chamar de Ética na Pesquisa abrange especificamente os procedimentos de proteção aos participantes de pesquisa diante dos riscos das pesquisas envolvendo seres humanos ${ }^{2}$. É sobre este domínio de preocupações e procedimentos que versa a Resolução 466/2012 do CNS e de onde derivam os protocolos e procedimentos de regulação da pesquisa pelo sistema dos Comitês de Ética na Pesquisa em seres humanos (CEPs) e animais (CEUAs), associados à Comissão Nacional de Ética em Pesquisa (CONEP) do CNS, constituindo o chamado sistema CEP-CONEP ${ }^{3}$. É deste domínio denominado Ética na Pesquisa no circuito da regulação da pesquisa no Brasil que trataremos neste artigo (BEVILAQUA, 2010). Buscando contribuições de outras áreas das Ciências Humanas, sobretudo nas experiências e nos debates desenvolvidos pela Antropologia, analisaremos os impasses que os pesquisadores dos Programas de Pós-Graduação em Educação vêm enfrentando por conta dos vieses institucionais e políticos no âmbito da definição dos parâmetros deste sistema de regulação.

\section{Introdução}

As Diretrizes e Normas Regulamentadoras de Pesquisas em Seres Humanos, instituídas pela Resolução CNS196/1996 (BRASIL, 1996) e reformulada pela Resolução CNS 466/2012 (BRASIL, 2012) do Ministério da Saúde, constituem um marco legal reconhecido como de grande valor pela

\footnotetext{
${ }^{1}$ Sobre o plágio, ver os artigos de Pitham e Oliveira (2013) e Pitham e Vidal (2013), bem como o documento de orientações da CAPES para o combate ao plágio (CAPES, 2011). Sobre integridade na pesquisa ver a declaração do II Braz̧ilian Meeting on Research Integrity, Science and Publication Ethics (BRISPE, 2012) e as diretrizes apontadas pelo Relatório da Comissão de Integridade de Pesquisa do CNPq (CNPQ, 2011).

2 Para uma discussão sobre as noções de "risco mínimo" e "risco mais que mínimo", ver Guilhem e Novaes (2010).

${ }^{3}$ O sistema CEP-CONEP, conforme definido no item VII da Resolução 466/2012: "É integrado pela Comissão Nacional de Ética em Pesquisa - CONEP/CNS/MS do Conselho Nacional de Saúde e pelos Comitês de Ética em Pesquisa - CEP - compondo um sistema que utiliza mecanismos, ferramentas e instrumentos próprios de inter-relação, num trabalho cooperativo que visa, especialmente, à proteção dos participantes de pesquisa do Brasil, de forma coordenada e descentralizada por meio de um processo de acreditação". (BRASIL, 2012).
} 
comunidade científica (SARTI; DUARTE, 2013; FLEISCHER; SCHUCH, 2010; GUERRIERO; SCHMIDT; ZICKER, 2008; VÍCTORA et al., 2004). Como sabemos, estas Resoluções expressam a história de um compromisso em favor dos direitos dos participantes de pesquisas - autonomia e informação e deveres da comunidade científica - não maleficência, responsabilidade, justiça e equidade quanto aos procedimentos e resultados da pesquisa (GUILHEM; NOVAES, 2010). Ao mesmo tempo, estão alinhadas ao repúdio histórico contra abusos cometidos contra estes valores. Tem por base o movimento em prol dos direitos humanos que se inicia no Pós-Guerra e, como declarado no próprio texto da Resolução CNS 466/12, evoca os documentos que marcam este movimento: Declaração de Helsinque, adotada em 1964 e suas versões de 1975, 1983, 1989, 1996 e 2000; o Pacto Internacional sobre os Direitos Econômicos, Sociais e Culturais, de 1966; o Pacto Internacional sobre os Direitos Civis e Políticos, de 1966; a Declaração Universal sobre o Genoma Humano e os Direitos Humanos, de 1997; e no campo da saúde: a Declaração Internacional sobre os Dados Genéticos Humanos, de 2003; e a Declaração Universal sobre Bioética e Direitos Humanos, de 2004.

Mesmo gozando de grande legitimidade, ao longo de seus 17 anos de existência, a Resolução CNS 196/1996 gerou uma série de reações devido às inadequações de seus procedimentos quando aplicados à pesquisa social. De um modo geral, é consenso entre os pesquisadores das Ciências Humanas e Sociais que a transposição do modelo de pesquisa biomédica para as bases epistemológicas, metodológicas e procedimentais das Ciências Humanas tem se mostrado pouco eficaz e, muitas vezes, um obstáculo para a realização de pesquisas. Este debate indica que a forma como esta resolução foi pensada e executada reproduz a separação, no âmbito da ciência moderna, entre as Ciências Naturais e Sociais, em um momento histórico no qual o debate epistemológico tem privilegiado os valores de cientificidade que fundamentam as Ciências Naturais (FONSECA, 2010), e no qual há uma problemática sinergia entre tecnologia, conhecimento e mercado (CASTELFRANCHI, 2008). O debate sobre a não neutralidade da ciência foi contundente em identificar elementos éticos e políticos ocultados pelo sistema de purificação que, em última instância, tende a reforçar a hegemonia de princípios ideológicos que a "ciência" insiste em não assumir como parte de seu alicerce epistêmico (LATOUR, 2001).

Depois de passar por alterações nos anos de 2000, 2004 e 2008, em virtude das Resoluções CNS 303/2000 e CNS 404/2008, a CNS 196/96 foi revista e substituída pela Resolução CNS 466/2012. Esta revisão mobilizou a comunidade científica e gerou expectativas de uma maior adequação da regulação da pesquisa para as Ciências Humanas. A consulta pública ocorreu em 2011 e recolheu 1890 sugestões por via eletrônica e 18 documentos pelo 
Correio. As contribuições foram submetidas à análise do Encontro Nacional dos CEPs, o ENCEP, e resultou na resolução CNS 466/12. Esta resolução, contudo, não atendeu satisfatoriamente as demandas das Ciências Humanas, o que denota a falta de aparatos legais e institucionais que deem conta da multiplicidade das formas de se fazer ciência na contemporaneidade (FLEISCHER; SCHUCH, 2010; VÍCTORA et al., 2004) e das relações de poder que aí se interpõem (FONSECA, 2010). A nova resolução reconhece esta necessidade, mas a projeta para o futuro, indicando a necessidade de uma resolução complementar, como se pode ler no item XIII.3 desta peça legal (BRASIL, 2012):

XIII - Das resoluções e das normas específicas

XIII.3 - As especificidades éticas das pesquisas nas ciências sociais e humanas e de outras que se utilizam de metodologias próprias dessas áreas serão contempladas em resolução complementar, dadas suas particularidades.

Neste contexto, o FORPRED foi uma das entidades que se pronunciou publicamente em prol de uma resolução específica para a regulação da ética em Ciências Humanas, por moção aprovada na Assembleia da ANPED em 2012. Ao longo de 2013, alguns Programas de Pós-Graduação em Educação também realizaram debates em suas universidades sobre esta temática. Neste âmbito, destaca-se o evento "Diálogos com a Pesquisa" do Programa de Pós-Graduação em Educação da Unicamp que, juntamente com o Fórum Regional de Coordenadores de Programa de Pós-Graduação em Educação da ANPED (FORPRED-Sudeste), promoveu o "Seminário Ética na Pesquisa em Educação", em 07 de agosto deste ano, visando abrir a discussão à comunidade da educação e preparar o FORPRED-Sudeste para a reunião anual da ANPEd. Neste seminário, foi reforçada a necessidade de uma legislação complementar para a área de Ciências Humanas e Sociais ${ }^{4}$.

A questão, contudo, não se limita às propostas de uma resolução complementar específica para as Ciências Humanas, mas também cogita a saída da regulação da pesquisa social do Ministério da Saúde, portanto, seu desligamento do Conselho Nacional de Saúde e sua passagem para o Ministério da Ciência, Tecnologia e Inovação (MCTI). Entre as alternativas propostas, destaca-se também a criação de Comitês de Ética em Pesquisa específicos para a Pesquisa em Ciências Humanas e Sociais ${ }^{5}$. Apesar das dificuldades para sua introdução e de algumas polêmicas político-epistemológicas (FONSECA, 2010),

\footnotetext{
${ }^{4} \mathrm{O}$ evento contou com a participação da antropóloga Cynthia Sarti da UNIFESP, que tem estado presente em vários debates sobre regulação da pesquisa, levando as posições da Associação Brasileira de Antropologia, o Prof. Claudio Garcia Capitão, do Instituto de Infectologia Emílio Ribas, e o Prof. Newton Aquiles Von Zuben, da PUC Campinas. ${ }^{5}$ Para uma discussão específica sobre esta experiência, ver Diniz (2010). Esta autora aponta ainda que a cria-
ção de CEPs específicos funciona já há algum tempo e com eficácia no contexto argentino.
} 
esta possibilidade tem sido vista com bastante interesse por vários Programas, Institutos e Faculdades das áreas de Ciências Humanas e, como veremos adiante, este interesse também se manifesta nos PPGs em Educação.

Estas diferentes propostas, apesar das discordâncias, são unânimes em sinalizar a importância de questionarmos a aplicação do modelo biomédico às Ciências Humanas (DINIZ, 2008) e a necessidade das agências científicas reconhecerem a pluralidade de concepções epistemológicas de pesquisa. Com isto, reivindica-se também o consequente reconhecimento desta especificidade na área de influência procedimental do campo científico que regula o julgamento das pesquisas pelas Comissões de Ética em Pesquisa, as condições de publicação em periódicos científicos, as condicionalidades para os financiamentos de pesquisa, entre outros. Como podemos perceber, mais que uma questão meramente burocrática, as contingências deste momento histórico criam oportunidades para discutirmos conjuntamente questões políticas fundamentais, tais como a hierarquização das formas de saber, os destinatários do conhecimento produzido, bem como as finalidades e aspectos éticos do fazer científico diante da sociedade.

As dificuldades para se chegar a algum consenso, acerca da melhor solução para a regulação da ética na pesquisa, mostram a importância da instauração de um debate amplo, integrado e participativo, para que as diversas demandas e experiências possam ser socializadas, discutidas e analisadas coletivamente. Contudo, antes de discutirmos os argumentos em jogo, vejamos como nossos pares têm se posicionado e vivenciado as exigências do sistema CEP/CONEP nos PPGs em Educação.

\section{Os rebatimentos da regulação da ética na pesquisa no âmbito da Pós-Graduação em Educação}

Com vistas à produção de subsídios para a mesa da sessão especial da ANPED (citada acima), o FORPRED promoveu uma consulta sobre o tema da ética na pesquisa, por meio de formulário eletrônico, dirigido aos coordenadores de Programas de sua rede de filiados ${ }^{6}$. O Formulário foi enviado por e-mail, para resposta online, para 143 PPGs no Brasil. Responderam 84 Programas (58\%). Na tabela abaixo podemos identificar o perfil de curso dos respondentes.

\footnotetext{
${ }^{6}$ Devemos esta iniciativa ao professor Jefferson Mainardes, coordenador do FORPRED, que elaborou este formulário online e o enviou para os 143 PPGs associados. Recebemos os dados desta consulta com as perguntas fechadas já tabuladas e expressas em gráficos e tabelas, algumas das quais utilizamos neste tópico.
} 
Tabela 1 - Programas de Pós-Graduação no Brasil que responderam a Consulta do FORPRED segundo perfil de curso

\begin{tabular}{lcc}
\hline Mestrado Profissional & 9 & $11 \%$ \\
\hline \hline Mestrado Acadêmico & 38 & $45 \%$ \\
\hline \hline Mestrado e Doutorado & 35 & $42 \%$ \\
\hline Mestrado Profissional, Mestrado Acadêmico e Doutorado & 2 & $2 \%$ \\
\hline
\end{tabular}

Fonte: Consulta FORPRED 2013.

Quanto ao modo como o PPG lida com a informação e orientação sobre os procedimentos de regulação da ética na pesquisa junto aos seus alunos e professores, verificou-se que: 67 PPGs disponibilizam orientação explícita sobre a análise dos projetos pelo CEP e/ou possui documento específico sobre questões relativas à ética na pesquisa. Além disto, o questionário indica que, entre os respondentes:

a) 37 possuem orientação explícita com relação à análise dos projetos de pesquisa dos pós-graduandos pelo Comitê de Ética;

b) 53 utilizam a Plataforma Brasil';

c) Em 64 PPGs os projetos de pesquisa dos pós-graduandos são avaliados por Comitê de Ética da própria instituição;

d) 30 PPGs possuem um documento (ou documentos) no qual está explicitada a orientação aos pós-graduandos com relação a questões éticas da pesquisa.

Quanto à obrigatoriedade de submissão ao CEP, para 47 (56\%) dos PPGs respondentes há obrigatoriedade para projetos que envolvem pesquisas com seres humanos, e para 37 (44\%) o envio é opcional. Interessante observar que o cotidiano dos pesquisadores consultados revela um perfil significativamente dissonante diante da prescrição da Resolução 466/12, quando afirma que:

XII.2 - As agências de fomento à pesquisa e o corpo editorial das revistas científicas deverão exigir documentação comprobatória de aprovação do projeto pelo Sistema CEP/CONEP.

Este perfil se refletirá na conformação da ambiência acadêmica, restringindo, socializando e/ou incentivando os pós-graduandos para que se adequem às exigências de submissão de seus projetos de pesquisa ao CEP. Deste modo, quanto ao envio de projeto de pesquisa que envolva seres humanos ao comitê de ética, vemos que 47,6\% dos PPGs afirmaram que este procedimento é obrigatório para todos os alunos da pós-graduação, sendo que $37,44 \%$ o consideram opcional.

\footnotetext{
7 A Plataforma Brasil é um sistema nacional e unificado para o registro de pesquisas envolvendo seres humanos. Como disposto no item V da Resolução 466/2012: “A Plataforma BRASIL é o sistema oficial de lançamento de pesquisas para análise e monitoramento do Sistema CEP/CONEP” (BRASIL, 2012).
} 
A consulta FORPRED contou com uma pergunta aberta para que os PPGs relatassem informações relevantes sobre questões da ética na pesquisa, envolvendo eventos realizados, discussões, eventos, grupos de trabalho, comissões, documentos, posicionamentos a respeito dos problemas enfrentados ou dificuldades com a Plataforma Brasil. Dentre os respondentes, 42 PPGs preencheram esta questão. É significativo que 33 dos 42 respondentes consideram inadequado o modelo de pesquisa da área da saúde quando aplicado à educação. Além disto, relatam dificuldades com os procedimentos, prazos e exigências dos CEPs, bem como no preenchimento dos formulários eletrônicos da Plataforma Brasil. Dentre estes 33 respondentes, 6 PPGs mencionam a criação de Comitês específicos para Ciências Humanas, como uma alternativa possível para a superação destes problemas. Em algumas poucas respostas (3) aparece a demanda por maior informação sobre os critérios para decidir sobre o envio ou não de projetos de pesquisa para o CEP.

Tabela 2 - Questões relevantes sobre ética na pesquisa relatadas pelos PPGs em Educação na resposta aberta da Consulta FORPRED 2013

\begin{tabular}{l|c}
\hline \multicolumn{1}{c|}{ Respostas } & Número de PPGs \\
\hline $\begin{array}{l}\text { Inadequação do modelo da área a saúde aplicado à } \\
\text { educação. Dificuldades com a Plataforma Brasil, prazos e } \\
\text { procedimentos do Comitê de Ética. }\end{array}$ & 27 \\
\hline $\begin{array}{l}\text { Proposta de criação de Comitês específicos para Ciências } \\
\text { Humanas }\end{array}$ & 06 \\
\hline
\end{tabular}

Fonte: Consulta FORPRED 2013.

Embora pareça haver clareza por boa parte dos PPGs sobre o desajuste entre o modelo de pesquisa que fundamenta a regulação e aprovação de projetos pelos CEPs, as dificuldades com os protocolos são o ponto mais recorrente dentre as dificuldades sinalizadas. Isto nos leva a considerar que, muitas vezes, o peso dos procedimentos que são percebidos como burocracias impostas impedem que os verdadeiros "problemas éticos" sejam discutidos e considerados em toda sua pertinência. Os procedimentos para submissão (sobretudo a adequação de projetos fundamentados em metodologias qualitativas aos rígidos formulários da Plataforma Brasil) e a forma como são conduzidos os debates sobre os projetos de pesquisa que são submetidos aos CEPs incentiva pouco a discussão, nos termos que as instâncias acadêmicas estão acostumadas a realizar no campo das Ciências Humanas.

Neste sentido, o sistema CEP/CONEP não apenas limita a discussão ética e impõe dificuldades desnecessárias aos pesquisadores do campo da educação, mas também exige a adequação dos modos de pensar e fazer ciência a 
uma cultura acadêmica estranha e, até mesmo, avessa ao desenvolvimento das Ciências Humanas. Talvez por isto os professores estejam resistentes a submeter os projetos de seus alunos de mestrado e doutorado ao comitê de ética, pois este processo parece ser visto como uma imposição burocrática e gerencialista, e não uma confrontação com os dilemas éticos contemporâneos que poderia ampliar a abrangência analítica e a relevância social da pesquisa ${ }^{8}$.

É importante ressaltar que o campo da educação traz, historicamente, densas discussões sobre ética, e os pesquisadores não são, de maneira alguma, estranhos a este debate, mas temos que reconhecer que nos falta a socialização das perguntas e a sistematização de soluções locais e das consequências de experiências particulares que as relações entre pesquisa, aplicação e formulação de políticas públicas têm acarretado no âmbito da regulação da ética na pesquisa.

Por este motivo, ao invés de decidirmos definitivamente sobre uma separação fundamental entre Ciências Biomédicas e Sociais, ou ainda, sobre permanecermos com o mesmo modelo, talvez pudéssemos experimentar novas alternativas que vêm se configurando, como quem coletivamente tateia em um campo cujas respostas são construídas pelas contingências históricas e políticas e não estão completamente dadas. $\mathrm{O}$ fato de poucos programas de pesquisa terem relatado que possuem um documento específico com orientações sobre ética na pesquisa reforça nossa percepção de que este debate na educação está apenas começando.

A seguir, trataremos de alguns enfrentamentos destes problemas no campo da Antropologia que, até onde identificamos, foi a área que primeiro e mais fortemente assumiu o protagonismo na interpelação do sistema CEP/CONEP. Mapeamos as principais iniciativas e publicações sobre regulação da ética na pesquisa em Antropologia, para em seguida delinear uma síntese de tensões e argumentos construídos neste percurso.

\section{O enfrentamento da regulação da pesquisa pelo Sistema CEP/ CONEP na Antropologia}

Como sabemos, a Antropologia é uma área do conhecimento que se caracteriza pela pesquisa etnográfica. A imersão nas realidades pesquisadas é condição para a pesquisa de campo, o que contribui para o engajamento e o compromisso ético e político dos pesquisadores com as populações com quem produzem suas pesquisas. É pública a implicação dos antropólogos no Brasil com as populações

\footnotetext{
${ }^{8}$ Consideramos que este foi um dos principais ganhos do processo de avaliação instaurado por um comitê específico. Ao contrário da racionalidade instrumental que conduz os debates na maioria dos CEPs, neste comitê os passos metodológicos são debatidos e as sugestões de adequação, a partir de um processo reflexivo, não ficam reféns dos códigos de ética em pesquisa desenhados para o campo Biomédico (DINIZ, 2010).
} 
que investigam, o que se pode notar em seus posicionamentos na defesa dos direitos humanos das populações afetadas por grandes projetos de desenvolvimento - como no Projeto Belo Monte - das populações indígenas ameaçadas pela política fundiária e os interesses da agroindústria - como nos conflitos da Serra Raposa do Sol - entre outros conflitos socioambientais onde os antropólogos se posicionaram como atores políticos em favor das populações afetadas.

Hoje, nas Ciências Humanas de modo geral, inclusive a fronteira que separa o lugar da militância política e o do pesquisador se torna cada vez mais tênue e a definição de papéis mais complexa. Não raro, pesquisadores de um determinado tema também militam ou assumem publicamente posições políticas sobre este mesmo tema e, do mesmo modo, é comum ativistas irem para a universidade para estudar suas próprias práticas políticas. Ciência e senso comum se tornam, neste contexto, não apenas registros de conhecimento mais aproximados, mas principalmente associados e interdependentes (SANTOS, 1988). Como argumenta Schuch (2010), é paradoxal que a Antropologia seja interpelada por procedimentos de regulamentação que impõem uma definição dos sujeitos pesquisados a partir de sua vulnerabilidade, em um momento histórico no qual é mais forte que nunca o movimento de reavaliação das assimetrias na construção de representações sobre o "outro".

Deste modo, é importante demarcar que não se trata de recusar a regulação dos procedimentos éticos que preservem os interesses das populações pesquisadas. Ao contrário, a atuação da Associação Brasileira de Antropologia (ABA) mostra o intenso debate sobre a ética na pesquisa e a responsabilidade social e política dos pesquisadores com as populações com as quais estão implicados em suas pesquisas de campo. O código de ética do antropólogo data de 1988 (ABA, 1988) ${ }^{9}$. Exatamente por conta deste engajamento ético é que a ABA vem conduzindo sistematicamente, ao longo da última década, um processo de resistência e questionamento ao sistema CEP/CONEP (SARTI; DUARTE, 2013; FLEISCHER; SCHUCH, 2010b; VÍCTORA et al., 2004). Ao analisarmos este embate veremos sua pertinência para os diversos campos das Ciências Humanas e Sociais (GUERRIERO; SCHMIDT; ZICKER, 2008).

Os questionamentos da área da Antropologia às normatizações biomédicas sobre a regulação da pesquisa científica com seres humanos tem seu marco inicial em 2000, com a aprovação de uma moção da ABA contra a resolução 304/00 (BRASIL, 2000) da CONEP, que estabelecia as "Normas para Pesquisas Envolvendo Seres

\footnotetext{
${ }_{9}^{9}$ A constituição de 1988 também contextualiza avanços para o campo da ética na pesquisa, entre outros motivos, por reconhecer novos direitos e universalizar princípios de cidadania capazes de garantir a integridade dos seres humanos independente de classe, raça, gênero etc. (AMORIM; ALVES; SCHETTINO, 2010). Foi esta constituição que consolidou e ampliou o estado democrático no campo jurídico e político, incentivando formas de participação da sociedade (DALLARI, 2008).
} 
Humanos/área de Povos Indígenas”. Em 2001 a mesma postura é reiterada em oficio da ABA de 18/07/2001, assinado pelo presidente da ABA, na época Ruben Oliven, e dirigido ao Ministro da Saúde, na época José Serra, e ao presidente da CONEP, na época William Saad Hossne, em que se recomendava que "a proposta de Normas de Ética para Pesquisa em Populações Indígenas, então em vias de elaboração pela CONEP, fosse limitada à esfera da saúde como reza o item XVI, art. $3^{\circ}$ do Regimento Interno do Conselho Nacional de Saúde (Resolução 291/99), a Lei 8.080 de 19/9/90 e a Lei 8.142 de 29/12/90"10.

O que já estava em jogo era o questionamento da abrangência da normativa da CONEP que pretendia regular todas as áreas do conhecimento que pesquisassem tendo como sujeitos seres humanos. Contra o que a ABA entendia ser uma extrapolação das competências da CONEP, argumentava-se que a pesquisa antropológica em comunidades indígenas já estava submetida à regulação da FUNAI (portaria 745-88da), ao parecer favorável do CNPq e a uma comissão interinstitucional formada por diversas entidades cientificas como SBPC, ABA, ABRALIN, CNPq. Como vemos, não se trata apenas de regulação da pesquisa, pois as práticas da Antropologia já se encontravam reguladas por outras instituições. O que se iniciou em 1996 foi, na verdade, a centralização e burocratização das práticas de regulação científicas a partir de um modelo empiricista de ciência. Não por outro motivo, o ser humano passa a ser entendido como um organismo, alvo do interesse e dos cuidados da saúde, em uma perspectiva reducionista biomédica e, na maior parte das vezes, medicamentosa (FONSECA, 2010).

$\mathrm{Na}$ década que se passou entre os anos 2000 e 2011, o debate parece ter se mantido dentro da área, com publicações e seminários a respeito (ver Anexo 1), mas sem outros enfrentamentos diretos com o Ministério da Saúde. Como sabemos, o CNS estabeleceu em 1996 a Resolução 196/96, que passou a regular toda a pesquisa com seres humanos em todas as áreas do conhecimento. Assim, o desconforto não se limitava à pesquisa com comunidades indígenas, nem apenas à Antropologia, mas afetava outras disciplinas também afeitas à pesquisa qualitativa, como Educação, Serviço Social, Psicologia, Letras, entre outras que não se encaixam com facilidade no modelo biomédico da CONEP.

As publicações e os seminários organizados pela ABA, bem como os organizados em outros $\operatorname{campos}^{11}$, tiveram um papel importante para expandir a

\footnotetext{
${ }^{10}$ Segundo relatos informais de membros da ABA, esta carta jamais foi respondida pelo Ministério da Saúde ou pelo CONEP.

${ }^{11}$ Ver, por exemplo, o livro organizado por Guerriero, Schmidt e Zicker (2008), fruto do I Seminário sobre ética em pesquisa em Ciências Sociais e Humanas na Saúde, realizado pelo Comitê de Ética em Pesquisa da Secretaria Municipal da Saúde de São Paulo e pelo Instituto de Psicologia da Universidade de São Paulo. Importante ressaltar que não fizemos um levantamento sistemático dos debates sobre regulação da ética em pesquisa e, deste modo, podemos ter omitido realizações importantes.
} 
discussão, integrando pesquisadores em diferentes regiões e universidades do Brasil, e iniciando um processo de sistematização das reflexões sobre o tema (SARTI; DUARTE，2013; FLEISCHER; SCHUCH，2010; GUERRIERO; SCHMIDT; ZICKER, 2008; VÍCTORA et al., 2004). Neste período, também tivemos como objeto deste debate o caso do Comitê de Ética em Ciências Humanas e Sociais, em funcionamento na UNB desde 2008, que vem tentando estabelecer critérios e protocolos de avaliação dos princípios éticos em projetos de pesquisa, mais apropriados aos parâmetros da pesquisa social. Esta experiência é relevante pois nos permite analisar, a partir de um caso concreto, as possibilidades e limitações para a criação de CEPs específicos, além de oferecer um modelo inicial para outros empreendimentos semelhantes ${ }^{12}$.

Em 2011, o Conselho Diretor da ABA aprovou uma nova moção com os seguintes pontos: apoio à preservação da Resolução 196/96 apenas para o controle das pesquisas biomédicas; recusa da manutenção da subordinação da pesquisa de Ciências Sociais e Humanas à lógica biomédica da mesma Resolução; disposição em participar da possível elaboração de outra regulamentação, específica de nossa área, fora do âmbito do Ministério da Saúde. A moção de 2011, aprovada pela Assembleia Geral da ANPOCS, dirige-se aos órgãos reguladores de pesquisa no sentido de pedir a criação de mecanismos próprios para as Ciências Humanas e para pesquisas "com", e não apenas "em" seres humanos. Neste momento, está colocada a possibilidade, também polêmica, de que a regulação da ética na pesquisa migre do Ministério da Saúde para o Ministério de Ciência e Tecnologia. Entretanto esta proposta, como veremos adiante, será retomada apenas em 2013.

Em agosto de 2011, ocorre em Brasília o "Seminário Temático Pesquisas em Ciências Sociais e Humanas: Revisão da Resolução" CNS 196/96 e, em setembro, em São Paulo, acontece o "I Encontro Extraordinário dos Comitês de Ética em Pesquisa do Sistema CEP-CONEP”. Neste encontro, foi constituído um Grupo de Trabalho da CONEP, constituído pela ABA e representantes de outras instituições, para a formulação de uma proposta de Resolução Complementar específica para a pesquisa social. Recentemente, em 11 de junho de 2013, aconteceu uma Reunião de Associações Científicas na UNB, que contou com a presença de representantes de 26 entidades, na qual se discutiu a criação de um "Código de Ética em Pesquisa nas Ciências Humanas" e a possibilidade de formação de um Conselho de Ética em Pesquisa junto ao Ministério da Ciência,

\footnotetext{
${ }^{12}$ Além de estar articulado com pesquisadores de todo o Brasil, em seu sítio virtual (http://www.cepih.org. br), este comitê disponibiliza informações valiosas sobre o debate no campo da ética na pesquisa, tais como artigos, livros, sites e documentos nacionais e internacionais. Para uma discussão mais detalhada, ver Diniz (2010).
} 
Tecnologia e Inovação (MCTI) ${ }^{13}$. Formou-se um Grupo de Trabalho responsável por sistematizar as contribuições das diferentes instituições e apresentar uma proposta consensual. Neste encontro é apresentada a ideia de criação do "Fórum de Associações das Ciências Humanas, Sociais e Ciências Sociais Aplicadas”, que seria um espaço político para fortalecer os interesses dos grupos de pesquisa neste campo.

Um ponto que avança sobre as discussões anteriores é alterar a regulação prescritiva por um mesmo Código de Ética para toda a pesquisa científica, e que seria acionado apenas em caso de denúncia de violação aos seus princípios. Vemos que a crítica à perspectiva biomédica de regulação se amplia em direção à sua aplicação normativa. Neste contexto, a saída para as Ciências Humanas se daria a partir de um modelo principialista de regulação ética, em outras palavras, atribui-se mais importância aos princípios éticos que às normas. Recupera-se deste modo, os valores que fundamentam os procedimentos de regulação. Importante ressaltar que esta proposta retorna, mais uma vez, à fragilidade de um acordo ético que repouse excessivamente no bom senso de cada pesquisador, o que pode recolocar o problema em outras bases.

A partir deste rápido apanhado do percurso da $\mathrm{ABA}$ no campo da regulação da ética em pesquisa, podemos perceber que as questões que atravessam este debate não são simples e envolvem mudanças institucionais complexas. Por este motivo, para municiar a continuação dessa luta, é importante que se disponha do máximo de informação sobre o modo e sobre as condições de funcionamento dos CEPs locais e do eventual trânsito de processos de autorização junto à CONEP (como no caso da pesquisa com "populações indígenas”). Veremos agora alguns argumentos que povoam os debates sobre ética na pesquisa e que consideramos especialmente pertinentes ao campo da educação.

\section{Uma síntese dos principais argumentos em jogo}

$\mathrm{Na}$ Sessão Especial sobre ética em pesquisa na $36^{\mathrm{a}} \mathrm{RA}$ da ANPEd, em 2013, o professor Aníbal Gil Lopes (UFRJ), representando a CONEP, iniciou sua apresentação com uma citação às duas culturas. Esta expressão foi cunhada pelo físico e romancista Charles Percy Snow, para analisar a distância entre a cultura científica e a cultura literária, e a dificuldade de construir um

\footnotetext{
${ }^{13}$ Um alerta importante que tem sido debatido sobre esta possibilidade diz respeito aos efeitos desta migração para as pesquisas biomédicas. Estando a regulação destas pesquisas no Ministério da Saúde, os critérios de regulação, apesar das críticas, estariam mais atrelados às exigências e demandas relacionadas à saúde e ao bem-estar dos indivíduos. No MCTI isto pode não ocorrer, e os critérios podem assumir um caráter mais comprometido com o desenvolvimento e o avanço tecnológico, deixando a estrutura institucional mais fragilizada frente à poderosa indústria farmacêutica, e outros gigantes do campo da pesquisa em seres humanos, e seus interesses econômicos.
} 
entendimento comum entre estas duas culturas (SNOW, 1995). Esta distinção também foi associada à distância entre Ciências Naturais/Exatas e Ciências Humanas, que é constitutiva da universidade moderna concebida por Wilhelm von Humboldt. O elemento diferencial desta universidade foi, além da antiga função de preparar para as profissões, a centralidade da pesquisa, a wissenschaft. Já em seu nascedouro, no início do século XIX, o campo da pesquisa estava tensionado entre duas vertentes diferentes: as Naturvissenschaften, ou Ciências Naturais, e as Geisteswissenschaften, ou Ciências Humanas e Sociais (FARR, 2008). Isto nos mostra que o problema subjacente à discussão sobre a regulação da ética na pesquisa encontra raízes profundas na história da modernidade, que determinam a maneira como a sociedade classifica e hierarquiza as diferentes formas de construção de conhecimento.

Buscando enfrentar este abismo histórico, Gil Lopes, de acordo com a postura pedagógica que foi assumida pela CONEP, reiterou a disposição para o diálogo e a abertura para o entendimento entre essas duas culturas. Contudo, apesar das sinceras intenções há uma distância instituída que permanece vigente entre as duas culturas. Isto produz efeitos importantes, como veremos em seguida, ao analisarmos os principais argumentos trazidos pelas Ciências Humanas e Sociais no questionamento à regulação da pesquisa a partir de princípios e protocolos criados para as Ciências da Vida ou Biociências.

\section{A crítica ao argumento biocêntrico e à extrapolação dos domínios da ordem biomédica}

Talvez o argumento mais eloquente que tem se evidenciado como origem do mal-estar nas Ciências Humanas diga respeito ao posicionamento do modelo biomédico como representante do núcleo de verdade e validade científica que, nesta condição, seria a base de toda ciência. Esta premissa fundamenta o alargamento deste modelo como base para a regulação de todo campo científico, o que irá impactar, além da regulação da ética na pesquisa, o financiamento de projetos, a avaliação dos cursos, os índices de produtividade etc. Estamos tratando do contexto brasileiro, entretanto é importante ressaltarmos que este processo de ampliação dos códigos de conduta baseados nas Ciências Naturais, acrescidos da lógica produtivista e de demandas por conhecimentos voltados para o mercado, está cada vez mais globalizado. Atinge até mesmo as mais tradicionais universidades europeias. Neste âmbito, destaca-se o Pacto de Bologna, comparável ao "Modelo Capes de Avaliação e Fomento", que intensifica os regimes de trabalho dos professores e pesquisadores universitários, em um processo caracterizado pela heteronomia e pela lógica de mercado (BIANCHETTI, 2010). 
Ao desconstruirmos o universo hierárquico de valores epistemológicos e sociais das políticas científicas, o que se evidencia é uma expansão indevida de um domínio de verdade sobre todos os outros. Tomemos como exemplo a própria noção de sujeito da pesquisa. O modelo biomédico tende a produzir efeitos de continuidade e equivalência entre as noções de indivíduo e organismo como objetos da pesquisa. Estes "indivíduos-organismos", por sua vez, participam de relações de causalidade como as que se estabelecem entre um fator patogênico e a resposta do organismo, ou ainda entre fatores ambientais e respostas cognitivo-comportamentais. Esta lógica, que faz sentido para investigações epidemiológicas e para produção de escalas psicológicas, por exemplo, tem pouco a dizer sobre pessoas e fenômenos culturais complexos tais como os encontros e desencontros multiculturais, relações interétnicas, modos de vidas que partilham de ontologias não ocidentais e constituem regimes de conhecimento diferentes daqueles dos que buscam conhecê-los.

A questão não é decidir pela matriz "mais científica", mas garantir a pluralidade de modelos de ciência à disposição das diferentes opções teórico-metodológicas. O problema é a redução das formas válidas do fazer cientifico "sobre/ com/em" seres humanos ao modelo biomédico. Isto provoca o que Oliveira (2004) chamou de extrapolação de domínios, ao identificar um viés biocêntrico na resolução 196/96, determinando o caráter da pesquisa:

Ao regular toda e qualquer pesquisa com seres humanos a resolução sugere um certo exagero ou uma certa extrapolação de domínios. Neste sentido, me parece que a resolução 196 expressa o que gostaria de caracterizar como um certo "areacentrismo" ou "biocentrismo" na visão sobre a ética, com implicações muito similares ao que nós na antropologia frequentemente nos referimos através da noção de etnocentrismo. (OLIVEIRA, 2004, p. 33).

Conforme o autor, trata-se, assim, de uma impostura no sentido de uma expansão ou presença não autorizada pelo "Outro". Uma situação que remete a conflitos análogos entre esferas profissionais dentro do próprio campo da saúde, tal como o que acompanhamos nos últimos anos com a tentativa de redução à ordem médica de toda intervenção na saúde humana. Referimo-nos aqui ao projeto de lei denominado "Ato Médico"14, recentemente aprovado e, felizmente, vetado em seus artigos mais controversos pela Presidente da República Dilma Rousseff. Os artigos vetados pretendiam submeter toda intervenção no campo da saúde, como aquelas praticadas por assistentes sociais, enfermeiros, psicólogos, fisioterapeutas, educadores físicos e outros, ao escrutínio e à autorização prévia por um médico.

\footnotetext{
${ }^{14}$ Projeto de Lei do Senado nº268/2002.
} 
Voltando para as disputas no campo da pesquisa, a "cultura científica"que alicerçou a resolução CNS 196/96, e segue vigente na atual CNS 466/12, não parece estar em questão. Discussões como as trazidas pelos estudos sociais da ciência, que tomam o fazer científico como prática cultural interessada, não parecem ter lugar no contexto desta guerra das ciências. O que move este cenário parece ser antes a luta por hegemonia na regulação do campo cientifico e o controle de seus dispositivos de legitimação como as agências de fomento, redes de pesquisa, circuitos editoriais e outras áreas de influência. Como já advertia Minayo (2008, p. 39)

Mesmo quando a biomedicina lança mão de alguns conceitos e métodos das ciências sociais, privilegia o positivismo e o funcionalismo sociológico, deixando de atentar para as tensões e os conflitos na sociedade, as determinações sociais da saúde/doença, assim como os aspectos da medicina como produção cultural.

Os desacordos acontecem na esfera da política científica justamente pela imposição ou extrapolação dos domínios de uma razão científica (biomédica) para todo o campo científico, como se apenas esta detivesse a chave de validação de um fazer científico apresentado como universal. Seríamos ingênuos se pensássemos que são, exclusivamente, os critérios epistemológicos que definem os princípios e procedimentos das políticas científicas. Este movimento se dá em duas direções, na qual um determinado modelo de ciência se mostra mais adequado às exigências político-econômicas (LATOUR, 2004). Não por outro motivo, vemos o alastramento da lógica quantitativista e empiricista, como a já mencionada adoção de lógicas de mercado no interior das políticas de educação (BIANCHETTI, 2010), apenas para citar um exemplo.

\section{Pesquisa em seres humanos, envolvendo seres humanos, com seres humanos}

A expressão pesquisa em seres humanos ou pesquisa em animais é a mais recorrente na área biomédica. É assim que se nomeiam os CEPs, por exemplo. A Resolução CNS 466/12, no item II.14, usa um termo um pouco mais amplo, que é pesquisa envolvendo seres humanos. Define este termo como "pesquisa que, individual ou coletivamente, tenha como participante o ser humano, em sua totalidade ou partes dele, e o envolva de forma direta ou indireta, incluindo o manejo de seus dados, informações ou materiais biológicos" (BRASIL, 2012). Este ser humano, que pode ser tomado em suas "partes", do qual podem ser extraídos dados, informações ou materiais biológicos, afasta-se do humano com que geralmente operam as Ciências Humanas e Sociais. No campo da educação, sobretudo, grande parte dos esforços teórico-metodológicos vai ao sentido de considerar o ser humano em sua totalidade e integrar as diferentes esferas da existência humana. 
$\mathrm{Na}$ literatura antropológica, tornou-se uma referência a distinção feita por Oliveira (2004) entre "Pesquisa em versus pesquisa com seres humanos" (OLIVEIRA, 2004, grifo no original). Nesta perspectiva, a pesquisa biomédica seria aquela tipicamente pensada como realizada em seres humanos, em que os seres humanos estariam no lugar de objetos do experimento científico e, portanto, em um lugar de participante passivo e de reduzida alteridade. A pesquisa com seres humanos pressupõe o pesquisador num contexto de interlocução com os participantes da pesquisa, pessoas com capacidade de diálogo e coprodução de conhecimento (OLIVEIRA, 2004). Neste sentido, a relação de pesquisa em Ciências Humanas tenderia a certa simetria entre diferentes saberes, diferentemente do modelo experimental biomédico. Por este motivo, expedientes como o assentimento e o consentimento tomam dimensões que nem sempre se resolvem num documento por escrito assinado no início da pesquisa. Como sintetiza Ribeiro (2004, p. 12) "o antropólogo em geral vive com quem ele pesquisa, e confiança é um truísmo, não se adquire de imediato”.

Por este motivo, vemos que este processo de regulação só atinge os pesquisadores vinculados ao sistema universitário, mostrando-se parcial, inclusive em sua percepção acerca do que seja a atividade de pesquisa. Como argumenta Oliveira (2010), um dos problemas do sistema CEP/CONEP é que ele só atinge as universidades e os institutos de pesquisa de maior destaque, não alcançando, por exemplo, as ONGs, algumas empresas e outros espaços que cada vez mais incorporam práticas de pesquisa em suas atividades. Este sistema não alcança, por exemplo, os pesquisadores que não possuem vínculos com instituições acadêmicas.

\section{O indivíduo esclarecido, livre e autônomo. A razão ilustrada e o Termo de Consentimento Livre e Esclarecido/TCLE como procedimento universal}

O Termo de Consentimento Livre e Esclarecido (TCLE) tem sido apontado como um dos principais complicadores para a adequação das pesquisas em Ciências Humanas ao modelo do CEP/CONEP (DUARTE; SARTI, 2013; FLEISCHER; SCHUCH, 2010; FONSECA, 2010; AGUIRRE, 2008). A exigência do TCLE estava na Resolução CNS 196/96 e permaneceu na Resolução CNS 466/2012. Em ambos os casos o TCLE é apresentado como mandatório e se prevê situações específicas em que este pode ser dispensado, desde que devidamente justificadas as razões pelo pesquisador. Vejamos em que situações esta "dispensa” é aceitável no tópico IV.8 desta última resolução:

IV.8 - Nos casos em que seja inviável a obtenção do Termo de Consentimento Livre e Esclarecido ou que esta obtenção signifique riscos substanciais à 
privacidade e confidencialidade dos dados do participante ou aos vínculos de confiança entre pesquisador e pesquisado, a dispensa do TCLE deve ser justificadamente solicitada pelo pesquisador responsável ao Sistema CEP/ CONEP, para apreciação, sem prejuízo do posterior processo de esclarecimento. (BRASIL, 2012).

A premissa da obrigatoriedade e universalização deste instrumento se reafirma neste item que regula sua "dispensa" para casos muito específicos, e é sempre seguida de justificada solicitação pelo pesquisador à instância reguladora. Uma condição que assegurasse a liberdade do pesquisador decidir pelo melhor formato do consentimento não parece ter lugar nesta Resolução. Uma situação diferente, por exemplo, pode ser vista no recente Código de Ética da "American Antropological Association" (AAA). Esta entidade estabeleceu como princípio que o consentimento não precisa ser necessariamente assinado e pode tomar diversas formas.

Entende-se que o grau e a amplitude do consentimento necessário dependerão da natureza do projeto e pode ser afetada por requisitos de outros códigos, leis e ética do país ou da comunidade em que a pesquisa é realizada. Além disso, entende-se que o processo de consentimento informado é dinâmico e contínuo, o processo deve ser iniciado na concepção do projeto e continuar com a execução por meio do diálogo e da negociação com os estudados. Os pesquisadores são responsáveis pela identificação e pelo cumprimento dos diversos códigos de consentimento informado, as leis e regulamentos que afetam seus projetos. O consentimento informado, para efeitos deste código, não implica, necessariamente, ou exige a forma escrita ou assinado particular. É a qualidade da autorização, não o formato, o que é relevante ${ }^{15}$ (AAA, 1998).

Oliveira (2010) discute esta inovação no código de ética da AAA e aponta que, mesmo não tendo poder coercitivo, expressa formas procedimentais mais articuladas aos dilemas enfrentados pelos antropólogos nas pesquisas de campo. Entretanto, apesar destas inovações, o autor ainda apresenta alguns casos de pesquisas que, para serem realizadas, desafiam este código de ética. Por exemplo, casos nos quais o pesquisador assume a identidade de nativo, dificultando a transparência para os participantes dos objetivos daquelainteração(HOONAARD, 2008). O mesmo acontece com pesquisas com atividades criminosas, tais como

\footnotetext{
${ }^{15}$ O Código de Ética profissional da American Anthropological Association (AAA), aprovado em 2012, regula o consentimento informado nos seguintes termos: "Anthropologists have an obligation to ensure that research participants have freely granted consent, and must avoid conducting research in circumstances in which consent may not be truly voluntary or informed. In the event that there search changes in ways that will directly affect the participants, anthropologists must revisit and renegotiate consent. The informed consent process is necessarily dynamic, continuous and reflexive. Informed consent does not necessarily imply or require a particular written or signed form. It is the quality of the consent, not its format, which is relevant." (AAA, 2012, p. 7).
} 
o tráfico de órgãos, utilizado como exemplo pelo autor, que exige engajamento do pesquisador e a supressão de sua identidade em determinadas interações de campo (OLIVEIRA, 2010). Na pesquisa em educação, podemos pensar em diversas situações semelhantes, tais como os casos nos quais o pesquisador atua profissionalmente em um campo que quer estudar, ou em pesquisas que tomam menores de idade como informantes, buscando estudar temas que seriam tabus para a família ou que levantassem suspeitas sobre contravenções ou atividades criminosas. Em escolas localizadas em zonas de alta periculosidade, geralmente sob pressão de traficantes ou milícias, a exigência de um TCLE tornaria praticamente impossível a realização de muitos recortes de pesquisa. Como vimos, em muitos contextos de pesquisa em Ciências Humanas, notadamente nas pesquisas de cunho etnográfico, a proposição de tal documento por parte do pesquisador, poderia criar um obstáculo à pesquisa, introduzindo suspeição, estranhamento e assimetria - efeitos não desejados no estabelecimento de uma relação de confiança e colaboração. Sobretudo quando imaginamos pesquisas com populações em conflito com a lei, populações não alfabetizadas ou mesmo com baixo domínio da língua portuguesa, como algumas populações indígenas ou grupos sociais marginalizados social e economicamente.

Assim, não se questiona a necessidade de fornecer informação sobre a pesquisa e a livre aceitação do participante em colaborar ou não com uma determinada proposta de investigação. Do mesmo modo, não está em questão o direito do participante da pesquisa ter acesso aos resultados do estudo para o qual colaborou e beneficiar-se deles (FERREIRA, 2010). Contudo, o que se põe em questão, no caso do sistema CEP/CONEP, é o caráter obrigatório e universalizante da assinatura de um documento por escrito, formulado dentro de regras discursivas e conteúdos de um ethos específico, aplicado no momento inicial da pesquisa. Neste contexto, Lima (2010) chega a questionar o funcionamento e a efetividade do sistema CEP/CONEP.

Cabe destacar finalmente que a noção de indivíduo autônomo, livre e esclarecido é tributária de uma tradição filosófica bastante situada na história ocidental, que pouco sentido faz para populações não ocidentais, tradicionais ou mesmo para grupos sociais que, vivendo no Ocidente, não "habitam", no sentido fenomenológico, a ontologia moderna ${ }^{16}$. Para estes grupos, a aplicação do TCLE pode ser não apenas um gesto destituído de sentido, como pode significar uma intervenção vivida como expressão indesejável de relações assimétricas.

Ambos, pesquisador e pesquisado, são produtores de conhecimento e a pesquisa deve ser vista como uma interlocução, um "diálogo". Os sujeitos e as relações são processuais, as possibilidades de reconhecimento e/ou de

\footnotetext{
${ }^{16}$ Sobre este tema, ver o artigo de Silva (2012) sobre o conceito de autonomia kantiano e sua distância das narrativas das populações brasileiras em situação de vulnerabilidade e exclusão.
} 
antagonismo vão emergindo na medida em que as relações se constroem no campo de pesquisa. Por este motivo, a percepção de que a assinatura de um "termo de consentimento livre e esclarecido" encerre os dilemas éticos de uma pesquisa seria ingênua e artificial. Ao contrário, muitas vezes a exigência de assinatura de um documento deste tipo pode, inclusive, colocar os interlocutores em risco e causar prejuízos de ordem física, psicológica, social, econômica, em temas delicados como gravidez na adolescência, homossexualidade, violência doméstica, tráfico de drogas, e outros (LISBOA; HABIGZANG; KOLLER, 2008; SILVEIRA; LUPPI; CARNEIRO JUNIOR, 2008).

Esta visão formal de regulação das relações entre pesquisadores e sujeitos de pesquisa, na verdade produz um "curto circuito". Ao burocratizar os procedimentos éticos, fecha espaços para a reflexão, o exercício do bom senso e a autonomia do pesquisador. Estes procedimentos podem, inclusive, desqualificar o comprometimento ético do pesquisador, desobrigando-o de expor as relações de poder que constituíram o contexto de pesquisa e condicionaram a autonomia e a vulnerabilidade dos sujeitos em interação. Mais uma vez, a normatização e o enfoque procedimental impedem, mais do que garantem, a lealdade aos princípios éticos da prática de pesquisa.

\section{Modelos metodológicos diversos e estranhamentos mútuos em contexto de assimetria no campo científico}

Como já apontou Minayo (2008), o cerne do dilema enfrentado atualmente nos Comitês de Ética pode ser compreendido como um conflito entre fundamentos epistemológicos. O campo biomédico, segundo a autora, está fundamentado pelo pragmatismo dos debates éticos anglo-saxões, ao passo que as Ciências Sociais estão fundamentadas, em sua maioria, pelas tradições filosóficas da Europa continental, que apresentam tradições como o existencialismo e a fenomenologia. A diferença entre os modelos metodológicos, como os de tipo experimental-estatístico das pesquisas epidemiológicas na saúde e o qualitativo-hermenêutico das pesquisas em Ciências Humanas, levam a territórios igualmente diversos de técnicas procedimentais. Histórias de vida, entrevistas narrativas abertas, entrevistas em profundidade ou semiestruturadas, grupos focais, observação participante e etnografias são procedimentos frequentes dos métodos de pesquisa social. Estes costumam, entretanto, causar estranhamento diante dos parâmetros de cientificidade-objetividade, amostragem válida, generalização de resultados, por exemplo, para quem trabalha baseado apenas como modelo experimental-estatístico.

Este é um nó que está no centro de muitas das dificuldades que afetam os pesquisadores das Ciências Humanas quando submetem seus projetos aos 
CEPs, que, apesar de obrigatoriamente interdisciplinares, acabam por se subscrever ao ethos das Ciências Naturais e Biomédicas. A observação participante e a etnografia podem ser consideradas os procedimentos metodológicos mais distantes do modelo de objetividade biomédica e, por isso, são os que suscitam os maiores equívocos neste embate epistêmico entre áreas do conhecimento. Como alertam MacRae e Vidal (2006, p. 653, grifo no original),

[...] projetos de pesquisa que investigam os aspectos culturais do uso de drogas e adotam métodos antropológicos, especialmente a observação participante, geralmente causam estranheza e até rejeição entre cientistas de outras disciplinas, como as da saúde, uma vez que muitas vezes não apresentam hipóteses formuladas a priori a serem testadas.

Considerações semelhantes são feitas por Zaluar (2012) sobre o trabalho de pesquisa com jovens em situação de vulnerabilidade, envolvidos com tráfico, uso de drogas e situações de violência. Tratando das especificidades da pesquisa participante, que apresenta grande flexibilidade metodológica diante das contingências dos campos de pesquisa, Schimidt e Toniette (2008, p. 105) argumentam que:

A ética na pesquisa pode ser entendida ou interpretada de modo exclusivamente regulador e normalizador, pressupondo que o pesquisador deva seguir, devotamente, condutas estabelecidas. Essa visão pode resvalar para a redução da ética aos procedimentos burocráticos e legalistas. A ética, quando forjada na heteronomia, de forma alienante, não garante a postura ética ao longo da pesquisa, mesmo após ter sido obtida a chancela 'ética'.

\section{Considerações finais}

Neste artigo, buscamos recuperar reflexões importantes que vêm sendo desenvolvidas no campo das Ciências Humanas e Sociais, de modo a contribuir para este debate na área da educação. Um ponto nos parece central: para pensarmos a regulação da ética na pesquisa, esta deve ser vista como a ponta de um iceberg, que traz submersas diversas questões de ordem epistemológica, culturais e, acima de tudo, políticas e econômicas. Mais que discutir as formas de regulação da ética na pesquisa e suas implicações para o fazer científico, neste momento é providencial refletirmos sobre as implicações do fazer científico nas diversas esferas atravessadas por ele. Não apenas o impacto do fazer científico no corpo dos indivíduos, mas o lugar da ciência e do fazer científico no projeto de sociedade em curso e na que queremos construir. Esta questão está amplamente abordada na bibliografia que encontramos e constitui o pano de fundo mais amplo sobre o qual devemos debater a regulação da ética na pesquisa. 
Se tomamos os argumentos de Vieira (2010), Porto (2010), Fonseca (2010), entre outros, nos questionaremos se as exigências deste modelo de transparência na regulação da pesquisa em Ciências Humanas não estariam, no limite, protegendo atores poderosos e que deveriam ser escrutinados pela atividade de pesquisa:

Não estamos deixando as instituições médicas blindadas do escrutínio científico das ciências humanas e sociais? Com certeza, os objetivos da Resolução CNS 196/1996 não se relacionam a isso, mas, na prática, têm dado margem para se proteger grupos de interesse nada vulneráveis. [...] corre o risco de corroborar para a obstaculização de investigações de grande interesse público. (VIEIRA, 2010, p. 139).

Deste modo, consideramos oportuno trazermos para o centro da discussão as especificidades da pesquisa em educação e aprimorarmos nossos argumentos. O que seria uma regulamentação apropriada ao campo da educação? Como conciliar os aspectos éticos com as tradições de pesquisa em educação? Como a dimensão inter e multidisciplinar que caracteriza a pesquisa em educação pode, neste contexto, fortalecer o diálogo e a presença da educação no campo das Ciências Sociais e Humanas? Quais são os destinatários e os agentes de poder que atravessam o campo da educação?

O que está em jogo na regulação da ciência não é separar os modelos de ciência, mas pensar sobre o processo de construção e o destino do conhecimento. Apenas alterar o código de ética seria insuficiente. O desejável é que este debate proporcione mudanças na correlação de forças entre os campos epistêmicos em disputa e seus agentes. Assim, o que está implícito na demanda por revisão dos parâmetros de regulação da pesquisa ao habitus das Ciências Humanas é o reconhecimento de um modo de produzir conhecimento válido no campo científico e engajado no plano social e político. Formulários mais flexíveis e compatíveis com metodologias qualitativas, critérios de avaliação da produção que alcancem melhor a qualidade e a quantidade do trabalho em cada pesquisa seriam marcadores deste reconhecimento. Pensamos que é esta a reivindicação dos pesquisadores em Ciências Humanas e Sociais, entre os quais nós, educadores, nos situamos.

\section{Referências}

AAA. Code of ethics of the American Anthropological Association. American Anthropological Association, 1998.

AAA. American Anthropological Association. Statement on Ethics: Principles of Professional Responsibilities. Arlington, VA: American Anthropological Association, 2012. Disponível em: <http://www.aaanet.org/profdev/ethics/upload/Statement-on-EthicsPrinciples-of-Professional-Responsibility.pdf>. Acesso em: 13 jan. 2014. 
ABA. Código de Ética do Antropólogo. Associação Brasileira de Antropologia, Brasília, 1988.

AGUIRRE, A. O termo de consentimento livre e esclarecido: desafios e dificuldades em sua elaboração. In: GUERRIERO, I.; SCHMIDT, M.; ZICKER, F. (Orgs.) Ética nas pesquisas em Ciências Humanas e Sociais na Saúde. São Paulo: Aderaldo \& Rothschild, 2008. p. 206-222.

AMORIM, E.; ALVES, K.; SCHETTINO, M. A Ética na pesquisa antropológica no campo pericial. In: FLEISCHER, S.; SCHUCH, P. (Orgs.) Ética e regulamentação na pesquisa antropológica. Brasília: Letras Livres; Editora da UnB, 2010. p. 193-216.

BEVILAQUA, C. Ética e planos de regulamentação da pesquisa: princípios gerais, procedimentos contextuais. In: FLEISCHER, S.; SCHUCH, P. (Orgs.) Ética e regulamentação na pesquisa antropológica. Brasília: Letras Livres e Editora da UnB, 2010. p. 71-90.

BIANCHETTI, L. O Processo de Bolonha e a intensificação do trabalho na universidade: entrevista com Josep M. Blanch. Educação \& Sociedade, Campinas, v. 31, n. 110, jan./mar. 2010. p. 263-285.

BRASIL. Lei $\mathbf{n}^{\mathbf{0}} \mathbf{8 . 0 8 0} / \mathbf{1 9 9 0}$. Dispõe sobre as condições para a promoção, proteção e recuperação da saúde, a organização e o funcionamento dos serviços correspondentes e dá outras providências. Presidência da República/Casa Civil/Subchefia para Assuntos Jurídicos. Brasília, 19 set. 1990.

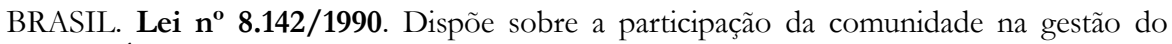
Sistema Único de Saúde (SUS) e sobre as transferências intergovernamentais de recursos financeiros na área da saúde e dá outras providências. Presidência da República/Casa Civil/ Subchefia para Assuntos Jurídicos. Brasília, 28 dez. 1990.

BRASIL.Resolução 196/1996. Diretrizes e normas regulamentadoras de pesquisas envolvendo seres humanos. Ministério da Saúde/Conselho Nacional de Saúde, Brasília, 10 out. 1996.

BRASIL. Resolução 304/2000. Norma complementar para a área de pesquisas em povos indígenas. Ministério da Saúde, Conselho Nacional de Saúde, Brasília, 9 ago. 2000.

BRASIL.Projeto de Lei do Senado $\mathbf{n}^{\mathbf{0} 268 / 2002}$. Dispõe sobre o exercício da Medicina. Senado Federal /Secretaria-Geral da Mesa. Brasília, 12 dez. 2002.

BRASIL. Resolução 466/2012. Diretrizes e normas regulamentadoras de pesquisas envolvendo seres humanos. Ministério da Saúde/Conselho Nacional de Saúde, Brasília, 12 dez. 2012.

BRISPE. Brazilian Meeting on Research Integrity, Science and Publication Ethics. Declaração Conjunta sobre Integridade em Pesquisa do II Encontro Brasileiro de Integridade em Pesquisa, Ética na Ciência e em Publicações. Rio de Janeiro, 29 maio 2012.

CAPES. Centro de Aperfeiçoamento de Pessoal de Nível Superior. Orientações Capes combate ao plágio. Brasília, 4 jan. 2011.

CASTELFRANCHI, Y. As serpentes e o bastão: tecnociência, neoliberalismo e inexorabilidade. 2008. 373 f. Tese (Doutorado em Sociologia) - Universidade Estadual de Campinas, São Paulo, 2008. 
CNPQ. Conselho Nacional de Desenvolvimento Científico Tecnológico. Relatório da Comissão de Integridade de Pesquisa do CNPq. Brasília, 7 out. 2011.

DALLARI, S. A proteção do direito à intimidade, a confidencialidade e o sigilo nas pesquisas em saúde. In: GUERRIERO, I.; SCHMIDT, M.; ZICKER, F. (Orgs.) Ética nas pesquisas em Ciências Humanas e Sociais na Saúde. São Paulo: Aderaldo \& Rothschild, 2008. p. 53-82.

DINIZ, D. Ética na pesquisa em Ciências Humanas: novos desafios. Ciência e Saúde Coletiva, Rio de Janeiro, v. 13, n. 2, p. 417-426, mar./abr. 2008.

DINIZ, D. A pesquisa social e os comitês de ética no Brasil. In: FLEISCHER, S.; SCHUCH, P. (Orgs.). Ética e regulamentação na pesquisa antropológica. Brasília: Letras Livres e Editora da UnB, 2010. p. 183-192.

FARR, R. Raízes da psicologia social moderna. Rio de Janeiro: Vozes, 2008.

FERREIRA, L. A dimensão ética do diálogo antropológico: aprendendo a conversar com o nativo. In: FLEISCHER, S.; SCHUCH, P. (Orgs.) Ética e regulamentação na pesquisa antropológica. Brasília: Letras Livres; Editora da UnB, 2010. p. 141-158.

FLEISCHER, S.; SCHUCH, P. (Orgs.) Ética e regulamentação na pesquisa antropológica. Brasília: Letras Livres; Editora da UnB, 2010.

FLEISCHER, S.; SCHUCH, P. Apresentação: Antropologia, ética e regulamentação. In: FLEISCHER, S.; SCHUCH, P. (Orgs.) Ética e regulamentação na pesquisa antropológica. Brasília: Letras Livres; Editora da UnB, 2010. p. 9-24.

FONSECA, C. Que ética? Que ciência? Que sociedade? In: FLEISCHER, S.; SCHUCH, P. (Orgs.). Ética e regulamentação na pesquisa antropológica. Brasília: Letras Livres e Editora da UnB, 2010. p. 39-70.

GUERRIERO, I.; SCHMIDT, M.; ZICKER, F. (Orgs.) Ética nas pesquisas em Ciências Humanas e Sociais na Saúde. São Paulo: Aderaldo \& Rothschild, 2008.

GUILHEM, D.; NOVAES, M. Ética e pesquisa social em saúde. In: FLEISCHER, S.; SCHUCH, P. (Orgs.). Ética e regulamentação na pesquisa antropológica. Brasília: Letras Livres; Editora da UnB, 2010. p. 217-236.

HOONAARD, W. A explosão da bolha: relações entre pesquisador e participantes pesquisados. In: GUERRIERO, I.; SCHMIDT, M.; ZICKER, F. (Orgs.). Ética nas pesquisas em Ciências Humanas e Sociais na Saúde. São Paulo: Aderaldo \& Rothschild, 2008. p. 83-101.

LATOUR, B. Jamais fomos modernos: ensaio de Antropologia simétrica. Rio de Janeiro: Editora 34, 2001.

LATOUR, B. Políticas da natureza: como fazer ciência na democracia. Bauru: Edusc, 2004.

LIMA, R. Até onde funciona? Uma breve reflexão sobre a atuação dos comitês de ética em pesquisa no estudo Antropológico em saúde. In: FLEISCHER, S.; SCHUCH, P. (Orgs.) Ética e regulamentação na pesquisa antropológica. Brasília: Letras Livres; Editora da UnB, 2010. p. 159-170.

LISBOA, C.; HABIGZANG, L.; KOLLER, S. Ética na pesquisa com temas delicados: estudos em psicologia com crianças e adolescentes e violência doméstica. In: GUERRIERO, I.; SCHMIDT, M.; ZICKER, F. (Orgs.) Ética nas pesquisas em Ciências Humanas e Sociais na Saúde. São Paulo: Aderaldo \& Rothschild, 2008. p. 176-192. 
MACRAE, E.; VIDAL, S. Resolução 196/96 e a imposição do modelo biomédico na pesquisa social: dilemas éticos e metodológicos do antropólogo pesquisando o uso de substâncias psicoativas. Revista de Antropologia, São Paulo, v. 49, n. 2, p. 645-666, jul./dez. 2006.

MINAYO, M. Apresentação. In: GUERRIERO, I.; SCHMIDT, M.; ZICKER, F. (Orgs.) Ética nas pesquisas em Ciências Humanas e Sociais na Saúde. São Paulo: Aderaldo \& Rothschild, 2008. p. 13-18.

OLIVEIRA, L. R. Pesquisas $\mathrm{em}$ versus pesquisas com seres humanos. In: VÍCTORA, C., OLIVEN, R.; MACIEL, M.; ORO, A. (Orgs.) Antropologia e ética: o debate atual no Brasil. Niterói: EdUFF, 2004. p. 21-32.

OLIVEIRA, L. A Antropologia e seus compromissos ou responsabilidades éticas. In: FLEISCHER, S.; SCHUCH, P. (Orgs.) Ética e regulamentação na pesquisa antropológica. Brasília: Letras Livres; Editora da UnB, 2010. p. 25-38.

PITHAN, L.; OLIVEIRA, A. Ética e integridade na pesquisa: o plágio nas publicações científicas. Porto Alegra: Mímeo, 2013.

PITHAN, L.; VIDAL, T. O plágio acadêmico como um problema ético, jurídico e pedagógico. Direito \& Justiça, Porto Alegre, v. 39, n. 1, p. 77-82, jan./jun. 2013.

PORTO, D. Relato de uma experiência concreta com a perspectiva das Ciências da Saúde: construindo o antropological blues. In: FLEISCHER, S.; SCHUCH, P. (Orgs.) Ética e regulamentação na pesquisa antropológica. Brasília: Letras Livres e Editora da UnB, 2010. p. 101-126.

RIBEIRO, G. Prefacio. In: VÍCTORA, C.; OLIVEN, R.; MACIEL, M.; ORO, A. (Orgs.) Antropologia e ética: o debate atual no Brasil. Niterói: EdUFF, 2004. p. 9-12.

SANTOS, B. Um discurso sobre as ciências na transição para uma ciência Pós-moderna. Estudos Avançados, São Paulo, v. 2, n. 2, p. 46-71, maio/ago. 1988.

SARTI, C.; DUARTE, L. (Org.). Antropologia e ética: desafios para a regulamentação. Brasília: ABA, 2013.

SCHMIDT, M.; TONIETTTE, M. A relação pesquisador-pesquisado: algumas reflexões sobre a ética na pesquisa e a pesquisa ética. In: GUERRIERO, I.; SCHMIDT, M.; ZICKER, F. (Orgs.) Ética nas pesquisas em Ciências Humanas e Sociais na Saúde. São Paulo: Aderaldo \& Rothschild, 2008. p. 102-108.

SCHUCH, P. Comentário: multiplicando perspectivas e construindo verdades parciais. In: FLEISCHER, S.; SCHUCH, P. (Orgs.) Ética e regulamentação na pesquisa antropológica. Brasília: Letras Livres; Editora da UnB, 2010. p. 91-100.

SILVA, J. O. A autonomia kantiana e o enredo da exclusão: análise das condições sóciohistóricas brasileiras geradas pelo processo colonizador. Revista bioética, Brasília, v. 20, n. 1, p. 87-96, 2012.

SILVEIRA, C.; LUPPI, C.; CARNEIRO JUNIOR, N. Aspectos éticos nas pesquisas e na produção de conhecimentos junto a grupos em situação de vulnerabilidade social. In: GUERRIERO, I.; SCHMIDT, M.; ZICKER, F. (Orgs.) Ética nas pesquisas em Ciências Humanas e Sociais na Saúde. São Paulo: Aderaldo \& Rothschild, 2008. p. 158-166. 
SNOW, C. P. As Duas Culturas e uma segunda leitura: uma versão ampliada das Duas Culturas e a Revolução Científica. São Paulo: EDUSP, 1995.

VÍCTORA, C., OLIVEN, R.; MACIEL, M.; ORO, A. (Orgs.) Antropologia e ética: o debate atual no Brasil. Niterói: EdUFF, 2004.

VIEIRA, F. Desencontros e descaminhos de uma pesquisa sociológica em um hospital público. In: FLEISCHER, S.; SCHUCH, P. (Orgs.) Ética e regulamentação na pesquisa antropológica. Brasília: Letras Livres e Editora da UnB, 2010. p. 127-140.

ZALUAR, A. Pesquisando no perigo com jovens vulneráveis: que ética? In: TAQUETTE, S.; CALDAS, C. (Orgs.) Ética e pesquisa com populações vulneráveis. Rio de Janeiro: Editora da UERJ, 2012. p. 189-212. (Coleção Bioética em Temas, v. II).

Recebido em 10/10/2013

Aceito em 25/11/2013 